\title{
Responses of water use in Moso bamboo (Phyllostachys heterocycla) culms of different developmental stages to manipulative drought
}

\author{
Xi-Pin $\mathrm{Wu}^{1,2}$, Shirong Liu ${ }^{1,3^{*}}$, Junwei Luan ${ }^{1}$, Yi Wang ${ }^{1,2}$ and Chunju Cai ${ }^{1,2}$
}

\begin{abstract}
Background: Understanding the mechanisms underlying plant water use in response to drought is critical to predicting the trend of ecosystem development under a changing environment, while the responses of water use in clonal plants with interconnected ramets to drought are far less clear than trees.

Method: In this study, we conducted manipulated drought by excluding 50\% annual throughfall at a stand level in a Moso bamboo (Phyllostachys heterocycla) forest, to determine how water use of the Moso bamboo responds to drought stress, and whether bamboo culms of different developmental stages show synchronized responses given the existence of physiological integration. Three developmental stages of bamboo culms (i.e., young, mature and old) were investigated and measurements were made on sap flow density $\left(J_{s}\right)$, leaf water potential at predawn $\left(\psi_{\text {pre }}\right)$ and midday $\left(\psi_{\text {mid }}\right)$, leaf water potential at turgor loss $\left(\psi_{\text {TLP }}\right)$, leaf stomatal density and size, and the maximum stomatal conductance $\left(g_{w}(\max )\right)$ was calculated.

Results: Under the manipulative drought conditions, the values of $J_{s}$ significantly decreased in the mature culms but not in the young and old culms. $g_{w(\max )}$ remained unchanged in mature culms, and increased in the young and old culms. Drought significantly reduced $\psi_{\text {mid }}$ of the young culms, resulting in more negative $\psi_{\text {TLP }}$ in the young culms compared with the old ones.

Conclusions: The results imply that the young culms adopted the drought tolerance strategy, while the old culms tended to adopt the drought avoidance strategy. Both the young and old culms are capable of maintaining relatively stable $J_{s}$ under drought by structural and physiological adjustments. Our findings demonstrate the variable responses of water use in bamboo culms of different developmental stages to drought, suggesting an unsynchronized responses of water use to water stress among culms in clonal plants.
\end{abstract}

Keywords: Soil water stress, Water relations, Drought sensitivity, Physiological adjustments, Clonal plant

\section{Background}

Frequent and severe drought events triggered by climate change have been monitored in subtropical regions of China during the past half century (Zhou et al. 2011). Climate change model projections also indicate that the risk

\footnotetext{
* Correspondence: liusr@caf.ac.cn; liusr9311@163.com

'Key Laboratory of Bamboo and Rattan, International Centre for Bamboo and Rattan, Beijing 100102, China

${ }^{3}$ Key Laboratory of Forest Ecology and Environment, National Forestry and Grassland Administration, Institute of Forest Ecology, Environment and Protection, Chinese Academy of Forestry, Beijing 100091, China Full list of author information is available at the end of the article
}

of exacerbated drought events is very likely to double in Southwest China than the other regions of China (Wang and Chen 2014). These drought events are expected to endanger plant water use (Barbeta et al. 2015), water-carbon relations (Sevanto et al. 2014) and consequently affect forest ecosystem functions and services (Anderegg et al. 2013).

As one of the most important physiological characteristics, plant water use under drought stress was extensively studied, by evaluating water loss via transpiration estimated from sap flow monitoring and plant water status reflected by leaf water potential $\left(\psi_{\text {leaf }}\right)(\mathrm{Du}$ et al. 
2011; Meinzer et al. 2013; Grossiord et al. 2014; Meinzer et al. 2016; Yan et al. 2016). Investigations indicated that drought decreased sap flow and $\psi_{\text {leaf }}$ with varying degrees across both tree species growing in the same habitat (Forner et al. 2014; Bretfeld et al. 2018) and intraspecies individuals acclimating to different habitats (Attia et al. 2015; Hochberg et al. 2018). The different drought sensitivities in sap flow and $\psi_{\text {leaf }}$ among species could be attributed to the inherent difference in structural (e.g. stomatal density and size) (Pinheiro et al. 2005; Skelton et al. 2015) and physiological traits (e.g., $\left.\psi_{\text {TLP }}\right)$ related to water use. For instance, stomatal density and size predominantly determine the maximum stomatal conductance, and therefore, plants with lower stomatal density or smaller stomatal size would have a slight decrease in transpiration in response to drought (Liu et al. 2012; Lawson and Blatt 2014). On the other hand, plants with less negative $\psi_{\text {TLP }}$ could maintain relatively stable water status by earlier stomata closure under drought (Maréchaux et al. 2015). Similarly, there are plastic responses of stomatal density and size as well as $\psi_{\text {TLP }}$ to varying soil water conditions, leading to different sensitivities in sap flow and $\psi_{\text {leaf }}$ among intraspecies individuals (Fraser et al. 2009; Xu et al. 2009; Sun et al. 2014). Higher stomatal density, smaller stomatal size (Bosabalidis and Kofidis 2002) and more negative $\psi_{\text {TLP }}$ (Bartlett et al. 2014) would occur under inadequate soil water condition.

Despite considerable investigations on water use across different tree species and habitats in response to drought (Schultz 2003; Forner et al. 2014; Mata et al. 2014; Attia et al. 2015), it is still barely investigated how the clonal plants with interconnected ramets, respond to drought, and unclear whether intraspecies individuals growing in the same habitat show different responses in sap flow and $\psi_{\text {leaf }}$ to drought. Generally, the interconnected ramets of clonal plant are at different developmental stages which differ in resource acquisition due to their varying structural and physiological characteristics (Dong et al. 2015; Zhang et al. 2016; Zhang et al. 2017). Despite some studies have reported that there is water use integration among ramets of different developmental stages in response to soil water heterogeneity (van Kleunen and Stuefer 1999; You et al. 2013; Roiloa et al. 2014), little is known about the drought response of ramets of different developmental stages in a homogeneous habitat. As a typical clonal plant of Poaceae, bamboo normally form pure forest under intensive management regime, which is consist of culms of different developmental stages growing in an association from an interconnected network of rhizomes. Moso bamboo (Phyllostachys heterocycla), as one of the monopodial bamboo species for the production of shoots and culms, is widely planted in southwest China. Recent studies indicated that Moso bamboo culms at different developmental stages experienced diverse water use and carbon acquisition patterns (Song et al. 2016; Zhao et al. 2016; Zhao et al. 2017). The increasing risk of drought due to climate change in southwest China is likely to affect the growth and productivity of Moso bamboo plantation, and consequently bamboo-based industry development. Therefore, there is a need to study the physiological responses of Moso bamboo to drought, focusing on water use and foliar stomatal changes of the bamboo culms at different developmental stages. In this study, we set up a manipulated throughfall reduction experiment in a Moso bamboo forest. We aim to elucidate (1) how foliar stomatal structural and physiological characteristics (e.g., stomatal density, size and $\psi_{\mathrm{TLP}}$ ) of Moso bamboo respond to manipulated drought; and (2) the effects of manipulated drought on sap flow and $\psi_{\text {leaf }}$ of culms at different developmental stages; in order to answer (3) the water use differences among developmental stages of Moso bamboo in response to drought.

\section{Methods \\ Study site}

This study was conducted in Changning Bamboo Forest Ecosystem Research Station $\left(28^{\circ} 27^{\prime}-28^{\circ} 27^{\prime} \mathrm{N}, 105^{\circ} 00^{\prime}-\right.$ $\left.105^{\circ} 01^{\prime} \mathrm{E}\right)$ located in Changning county, Sichuan Province China. The study area is a humid mid-subtropical region characterized with continental monsoon climate. The mean annual air temperature and average annual precipitation are $18.3^{\circ} \mathrm{C}$ and $1141.7 \mathrm{~mm}$, respectively. The predominant soil in the study area is Cambisols (according to the Food and Agriculture Organization of United Nations and United Nations Educational, Scientific, and Cultural Organization soil classification system). Pure Moso bamboo forest is the dominant forest type in this county with variety of management intensities for different purposes (e.g. tourism, food production, or industrial bamboo material).

\section{Experimental design}

Four replications of permanent blocks with throughfall reduction (TRT) and control treatments of each $(20 \mathrm{~m} \times 20$ $\mathrm{m})$ were established in 2016. The TRT is imposed using plastic roofs made of polyolefin film attached to rails about $2 \mathrm{~m}$ above the ground, which drained the collected rain out of the plot. These roofs direct about $50 \%$ of throughfall away from the $20 \mathrm{~m} \times 20 \mathrm{~m}$ TRT area. The ambient plot served as a control without plastic roofs. To prevent from lateral water movement and get rid of the clonal integration from bamboos outside the plot, we trenched the plots and buried a $0.3 \mathrm{~cm}$ thick plus $80 \mathrm{~cm}$ depth PVC board along the trench leaving $10 \mathrm{~cm}$ height above the ground. The TRT was initiated in April 2017.

In experimental stands, newly emerging bamboos were tagged in spring of each year from 2014 to 2018. Three 
developmental stages of bamboo culms were identified. Those new culms reaching full height in current year were chosen as young culms. We defined 2-3 years old culms and older than four years as the mature and old, respectively. In total 72 culms were selected ( 3 culms for each developmental stage per plot) in 2017, and another 12 young culms (6 culms for each treatment) emerging in 2018 were also monitored subsequently.

\section{Meteorological observation}

Local climate data were continuously collected from an automatic weather station (Onset Computer Corporation, Pocasset, MA, USA), about $500 \mathrm{~m}$ away from the study plots, including photosynthetically active radiation (PAR, $\mu \mathrm{mol} \cdot \mathrm{m}^{-2} \cdot \mathrm{s}^{-1}$ ), air temperature $\left(\mathrm{T},{ }^{\circ} \mathrm{C}\right)$, relative humidity (RH, \%), wind speed (WS, mph), and precipitation (Precip., $\mathrm{mm}$ ). All the meteorological data were measured at $30 \mathrm{~s}$ intervals, and $30 \mathrm{~min}$ averages were recorded on the U30-NRC-000-10-S100-000 data logger (Onset Computer Corporation, Pocasset, MA, USA). Vapor pressure deficit (VPD, $\mathrm{kPa}$ ) was calculated from $\mathrm{T}$ and RH (Allen et al. 1998). Additionally, SM-150 T sensors (Delta-T Devices, Cambridge, UK) mounted at three measurement depths $(10,30,60 \mathrm{~cm})$ in each plot to measure the soil water content $\left(\mathrm{SWC}, \mathrm{m}^{3} \cdot \mathrm{m}^{-3}\right)$ and soil temperature $\left({ }^{\circ} \mathrm{C}\right)$ at $10 \mathrm{~s}$ intervals and a DL2e data logger (Delta-T Devices, Cambridge, UK) recorded data with every $30 \mathrm{~min}$ averages.

\section{Sap flow measurements}

Three bamboo samples at each age were selected in each plot to measure sap flow density. The measurements were conducted during growing seasons of 2017 and 2018. The sap flow was monitored using self-made thermal dissipation probes following Granier's prototype (Granier 1987). A probe set consists of two 10-mm long needles installing in vertical at $1.3 \mathrm{~m}$ height of each sample culm on the south side sheltering with a plastic box and a film to protect from rainfall, solar radiation and thermal gradient. The upper needle was heated with a 120-mA direct current, and the lower one remained unheated as a reference. The sap flow density was measured every $30 \mathrm{~s}$ and stored every $10 \mathrm{~min}$ using a data logger (DL2e, Delta-T Devices, Cambridge, UK). Due to the remarkable difference of the hydraulic traits between bamboo and the dicot species from which Granier's standard equation (Granier 1987) was derived, we used the calibrated equation described by Zhao et al. (2016) basing on monitoring sap flow in the $P$. pubesens with

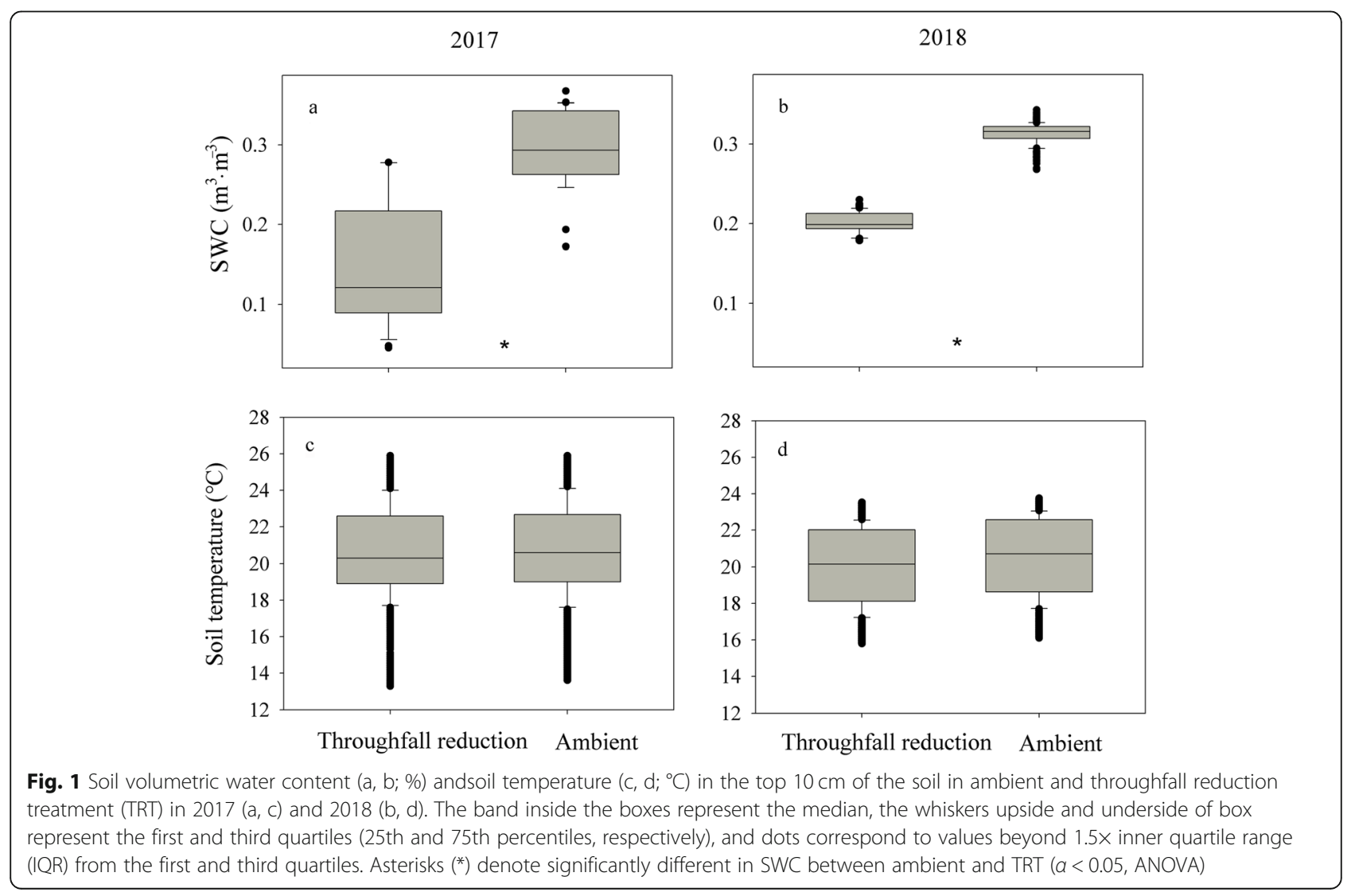


an accurate modified 10-mm probe. Thus, the sap flow density $\left(J_{\mathrm{s}}, \mathrm{g} \mathrm{H}_{2} \mathrm{O} \cdot \mathrm{m}^{-2} \cdot \mathrm{s}^{-1}\right)$ of $P$. pubesens equation (Zhao et al. 2016) is given as follows:

$$
J_{\mathrm{s}}=360.44 \times\left(\frac{\Delta T_{\mathrm{m}}-\Delta T}{\Delta T}\right)^{1.746}
$$

where $\Delta T_{\mathrm{m}}$ is the maximum temperature difference obtained under zero sap flow conditions and $\Delta T$ is the temperature difference between two needles; 360.44 and 1.746 are the suggested values for corrected empirical constants of original equation.

\section{Leaf water potential and turgor loss point measurement}

The $\psi_{\text {leaf }}$ was measured using a pressure chamber (SKPM1400, Skye, Llandrindod Wells, UK, $n>4$ for each developmental stages per treatment) at predawn (5:00-7: $00)$ and midday (11:00-13:00) in sunny days during June to August. The $\psi_{\text {leaf }}$ at the turgor loss or wilting point $\left(\psi_{\mathrm{TLP}}\right)$ was derived from pressure-volume curves described by Koide et al. (1989). Four to five healthy, non-necrotic and sunlit branches were excised in bamboo canopy of each developmental stage per treatment in the predawn after raining in 16th July, 2018. These branches were immediately re-cut underwater and rehydrated until $\psi_{\text {leaf }}>-0.05 \mathrm{MPa}$. After that, three shoots per branch were collected to be weighed and measured for $\psi_{\text {leaf }}$ repeatedly at regular time intervals until $\psi_{\text {leaf }}>-4 \mathrm{MPa}$. Then these shoots were weighted after being desiccated at $65^{\circ} \mathrm{C}$ for $48 \mathrm{~h}$. The pressure-volume curves were built with inverse $\psi_{\text {leaf }}$ and leaf relative water content. The distance from $\psi_{\mathrm{TLP}}$ was calculated as the difference between $\psi_{\text {TLP }}$ and $\psi_{\text {mid }}$.

\section{Stomatal density, size and $g_{\mathrm{w}(\max )}$ calculation}

Stomatal attributes were measured in leaves fully expanded and exposed to direct sunlight from seven culms of each developmental stage per treatment $(n=35$ leaves for each developmental stage classification per treatment).
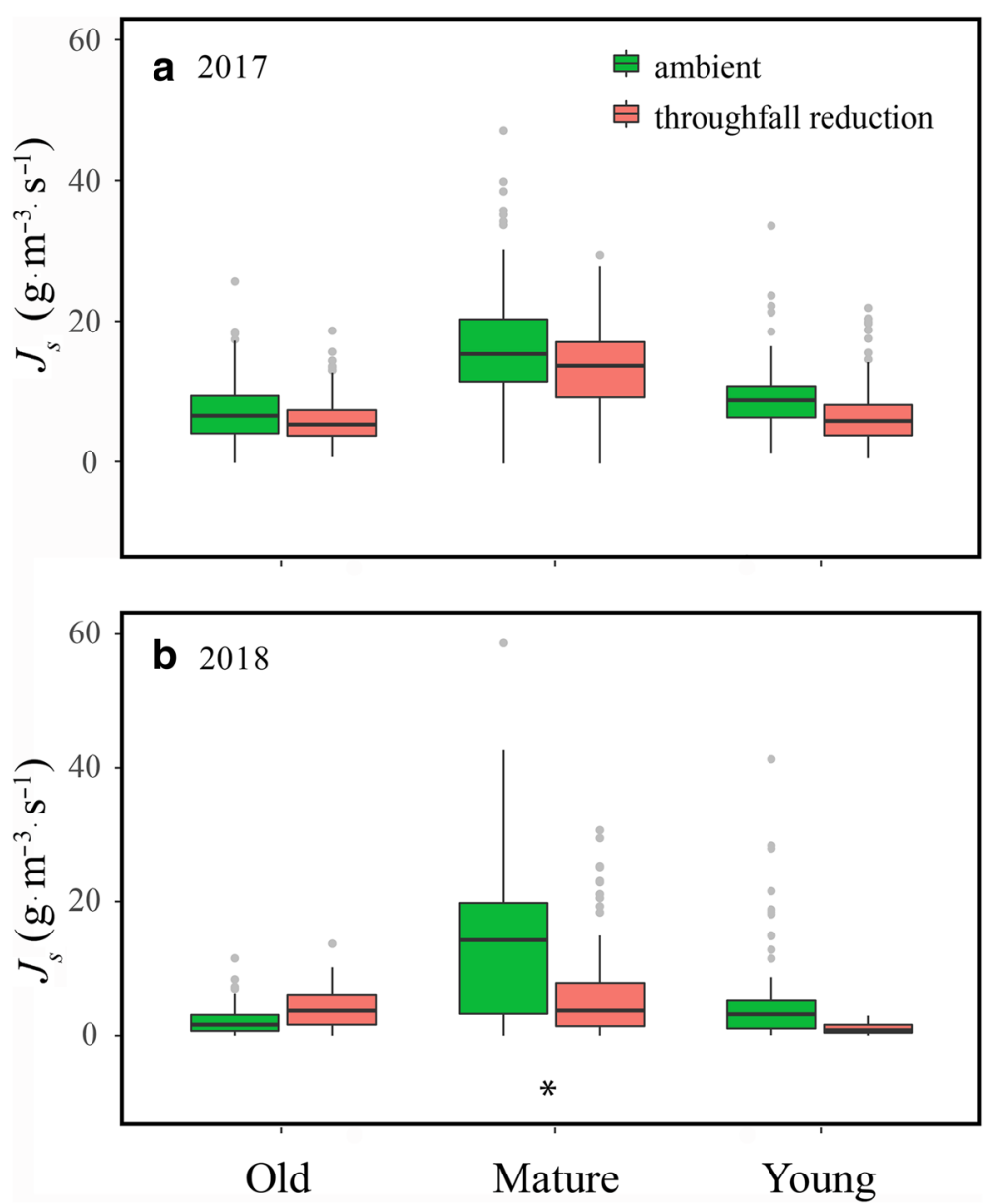

Fig. 2 Linear mixed model results of diel sap flow density in consecutive sunny days. The band inside the boxes represent the median, the whiskers upside and underside of box represent the first and third quartiles (25th and 75th percentiles, respectively), and dots correspond to values beyond $1.5 \times$ inner quartile range $(\mathrm{IQR})$ from the first and third quartiles. Asterisks $\left(^{*}\right)$ denote significantly different between ambient and throughfall reduction treatment (TRT) within a given developmental stage $(a<0.001$; Tukey method) 
Table 1 Relative importance metrics and confidence intervals

\begin{tabular}{|c|c|c|c|c|}
\hline \multirow{2}{*}{$\begin{array}{l}\text { Developmental } \\
\text { stages }\end{array}$} & \multirow[t]{2}{*}{ Predictor } & \multirow{2}{*}{$\begin{array}{l}\text { Relative } \\
\text { importance } \\
(\%)\end{array}$} & \multicolumn{2}{|l|}{$95 \% \mathrm{Cl}$} \\
\hline & & & Lower & Upper \\
\hline \multirow[t]{5}{*}{ Old } & PAR & 50.26 & 48.59 & 51.92 \\
\hline & VPD & 39.67 & 38.06 & 41.17 \\
\hline & Precip. & 5.77 & 4.19 & 7.45 \\
\hline & WS & 3.04 & 2.14 & 4.15 \\
\hline & SWC & 1.26 & 0.87 & 1.88 \\
\hline \multirow[t]{5}{*}{ Mature } & PAR & 54.98 & 53.51 & 56.39 \\
\hline & VPD & 35.02 & 33.7 & 36.25 \\
\hline & Precip. & 6.79 & 5.42 & 8.28 \\
\hline & WS & 2.6 & 1.91 & 3.39 \\
\hline & SWC & 0.62 & 0.41 & 0.96 \\
\hline \multirow[t]{5}{*}{ Young } & PAR & 53.37 & 51.67 & 54.87 \\
\hline & VPD & 36.88 & 35.49 & 38.36 \\
\hline & Precip. & 4.83 & 3.49 & 6.39 \\
\hline & WS & 2.73 & 2.02 & 3.63 \\
\hline & SWC & 2.19 & 1.46 & 3.15 \\
\hline
\end{tabular}

Methods are LMG (it decomposed $r^{2}$ to predictors into non-negative contributions that add up to overall model $r^{2}$ ). Data were collected from three developmental stages of culms ( $\left.N_{\text {young }}=36, N_{\text {mature }}=24, N_{\text {old }}=24\right)$. Predictors are vapor pressure deficit (VPD), photosynthetic active radiation (PAR), wind speed (WS), soil water content (SWC), and precipitation (Precip.)

Nail polish imprint was torn down from the abaxial leaf surface by a tweezer and then placed it under light microscopy (Olympus BX51, Tokyo, Japan) to calculate stomatal density $(D)$, guard cell pair width $(W)$ and length $(p)$ . Stomatal size was calculated as the guard cell pair width multiply guard cell length (Franks et al. 2015). $g_{\mathrm{w}(\max )}$ was calculated based on the formula (Franks et al. 2009):

$$
g_{\mathrm{w}(\max )}=\frac{d}{v} \cdot D \cdot a_{\max } /\left(l+\frac{\pi}{2} \sqrt{a_{\max } / \pi}\right)
$$

where $d$ is the diffusion coefficient of $\mathrm{H}_{2} \mathrm{O}$ in air $\left(\mathrm{cm}^{2} \cdot \mathrm{s}^{-1}\right), v$ is the molar volume of air $\left(\mathrm{m}^{3} \cdot \mathrm{mol}^{-1}\right), a_{\max }$ is the average value of maximum stomatal pore area, which, in Moso bamboo, is close to a circle with the stomatal pore length equal to a diameter, that is, $a_{\max }=$ $\pi p^{2} / 4, l$ is the stomatal pore depth, which is approximated as half of the stomatal width for fully hydrous guard cells (Franks and Farquhar 2007). All the leaves were collected in June 20th, 2018, when the renewed leaves had been mature.

\section{Statistical analysis}

One-way analysis of variance (ANOVA) was used to test the difference in SWC and ST between ambient and TRT. Two-way analysis of variance was used to identify the difference in stomatal density and size, $g_{\mathrm{w}(\max )}$ as well as $\psi_{\mathrm{TLP}}$ between the treatment and the developmental stages of culms. Repeated measures ANOVA was used to identify the difference in $\psi_{\text {leaf }}$ and its distance from $\psi_{\text {TLP }}$ between treatments in each developmental stages of culms. Linear mixed models were used to assess differences in $J_{\mathrm{s}}$ among the three developmental stages of culms. In the model, developmental stage, treatment and their interaction were fixed effects, and culms within each group were counted as a random effect. R-package "LME4" (Bates et al. 2015) was applied to perform Linear mixed model analyses and R-package "MULTCOMP" (Hothorn et al. 2008) was used to implement pairwise comparisons. To find out the environmental driver of $J_{\mathrm{s}}$, relative importance metrics of environmental factors were calculated applying LMG method (Lindeman et al. 1980) which divided model contribution among all predictors. Confidence intervals for relative importance metrics were obtained by bootstrapping (1000 runs). Linear regression models were built with meteorological factors (predictors) and average $J_{\mathrm{s}}$ (response) in the daytime of different developmental stages of culms per treatment, and analysis of covariance (ANCOVA) was performed to compare the slopes of the regressions lines to validate whether $\mathrm{J}_{\mathrm{s}}$ sensitivity to average VPD in the daytime and total daily PAR was different between treatments. Further, to test whether SWC impacts the variation of $\mathrm{J}_{\mathrm{s}}$ which VPD and PAR couldn't explain, we fitted linear models using the residuals $J_{\mathrm{s}}$ and average daily SWC. The residuals $J_{\mathrm{s}}$ generated by the linear regression of $J_{\mathrm{s}}$ and VPD as well as $J_{\mathrm{s}}$ and PAR. To clarify the sensitivity of $J_{\mathrm{s}}$ to $\psi_{\text {leaf }} J_{\mathrm{s}}$ at midday (11:00-13:00) and $\psi_{\text {mid }}$ were selected to build linear regression model for each developmental stage. The slopes of regression lines were compared by ANCOVA. All data analyses and graphics were performed in the statistical program R 3.4.3 (R Core Team 2017).

\section{Results}

\section{Soil temperature and moisture}

The TRT caused a significant decrease in SWC by $31.4 \%$ in 2017 and $35.6 \%$ in 2018 comparing with ambient treatment (all $p<0.01$; Fig. 1a and b). There was no inter-annually difference in average SWC between 2017 and $2018(p>0.05)$. Moreover, soil temperature was not affected by TRT ( $p>0.05$, Fig. 1c and d).

\section{Sap flow}

The TRT reduced $J_{\mathrm{s}}(p<0.05)$ of the mature rather than that of the old and young culms (Fig. 2b). The variation of $J_{\mathrm{s}}$ was best described by VPD and PAR (Table 1), and positive linear relationships between $J_{\mathrm{s}}$ and VPD (Fig. 3a, c, d) as well as $J_{\mathrm{s}}$ and PAR (Fig. 4a, c, d) were detected 


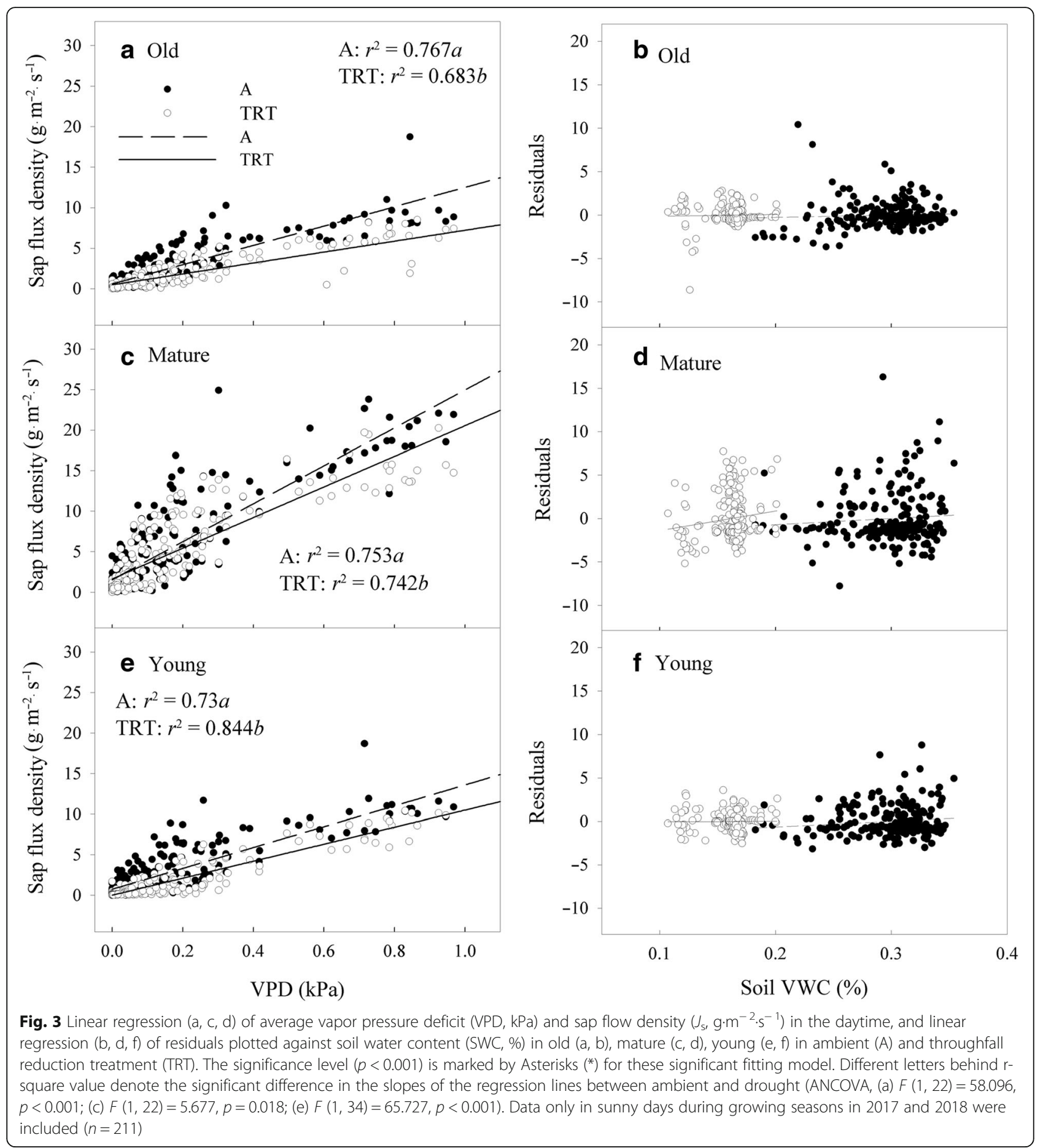

in three developmental stages of culms. In contrast, SWC could not explain the fluctuation of $J_{\mathrm{S}}$ (Table 1). Furthermore, when the effects of VPD and PAR were controlled, residual $J_{\mathrm{s}}$ could not explained by SWC as well (Fig. 3b, d, f, and 4b, d, f), suggesting SWC had no direct effect on $J_{\mathrm{s}}$. Interestingly, TRT significantly lowered the slopes of the relationships between $J_{\mathrm{s}}$ and VPD
(Fig. 3a, c, d), and the similar results occurred between $J_{\mathrm{s}}$ and PAR (Fig. 4a, c, d), suggesting TRT caused significant decreases in sensitivities of $J_{\mathrm{s}}$ to VPD and PAR.

Leaf water potential and $\psi_{\mathrm{TLP}}$

The TRT significantly decreased $\psi_{\text {mid }}$ of the mature and young culms (all $p<0.01$, Fig. $5 \mathrm{~b}, \mathrm{~d}, \mathrm{f}$ ) rather than that of 


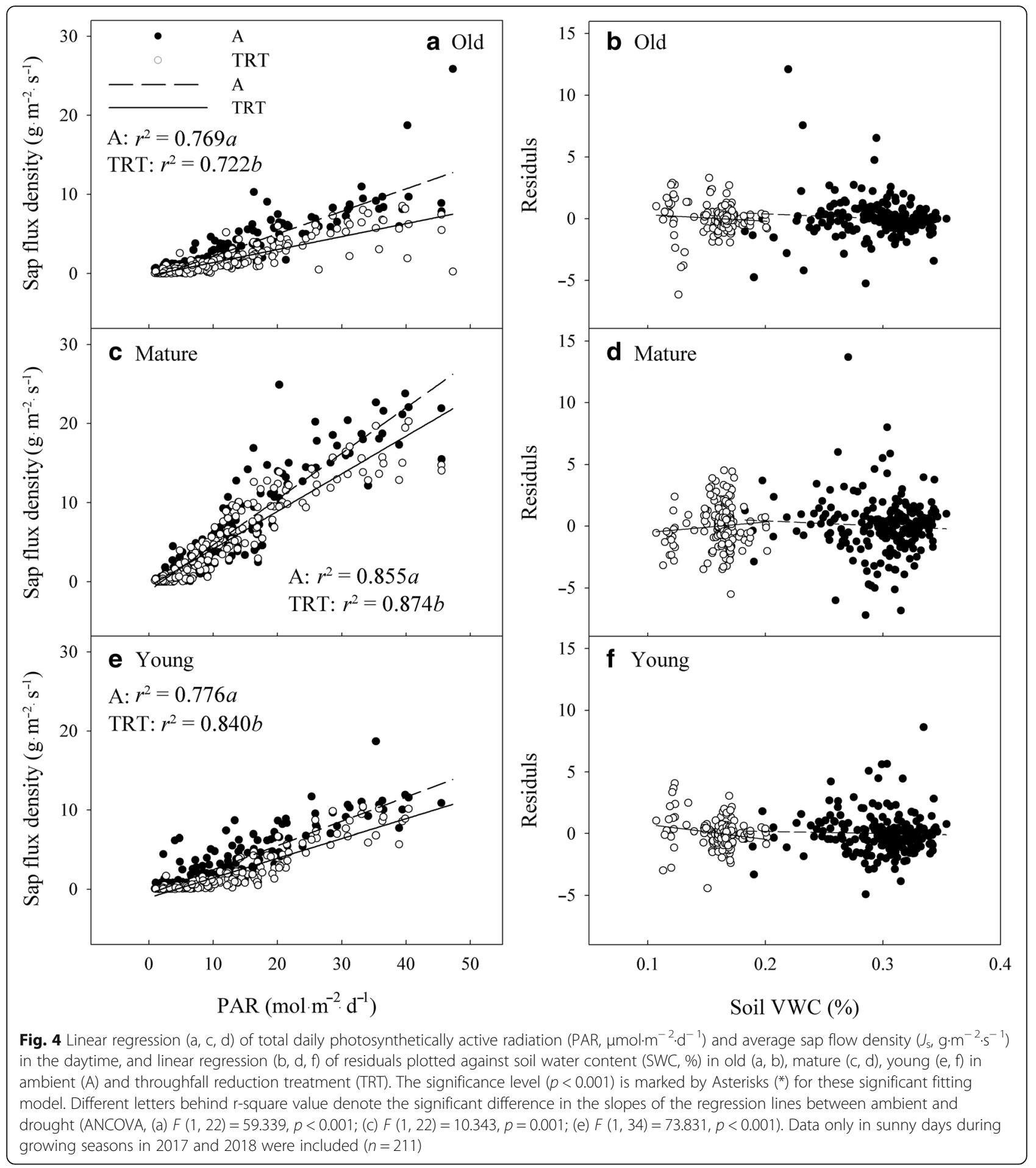

the old. Moreover, negative linear relationships between $J_{\mathrm{s}}$ and $\psi_{\text {mid }}$ were found for the three developmental stages of culms regardless of treatments (Fig. 6), and the slope for the old culms was higher than that of the young culms both in ambient and TRT (A: $p<0.01$, TRT: $p=0.04$, ANCOVA). Additionally, the TRT decreased $\psi_{\text {TLP }}$ irrespective of developmental stages of culms (all $p<0.01$, Fig. 7) and the $\psi_{\text {TLP }}$ in the old culms was the least negative in the three developmental stages of culms (all $p<$ 0.01 ), suggesting that the stomata of the old culms close earliest under drought. The distance from $\psi_{\mathrm{TLB}}$ indicating that the stomatal aperture, decreased in all developmental 
ambient

throughfall reduction
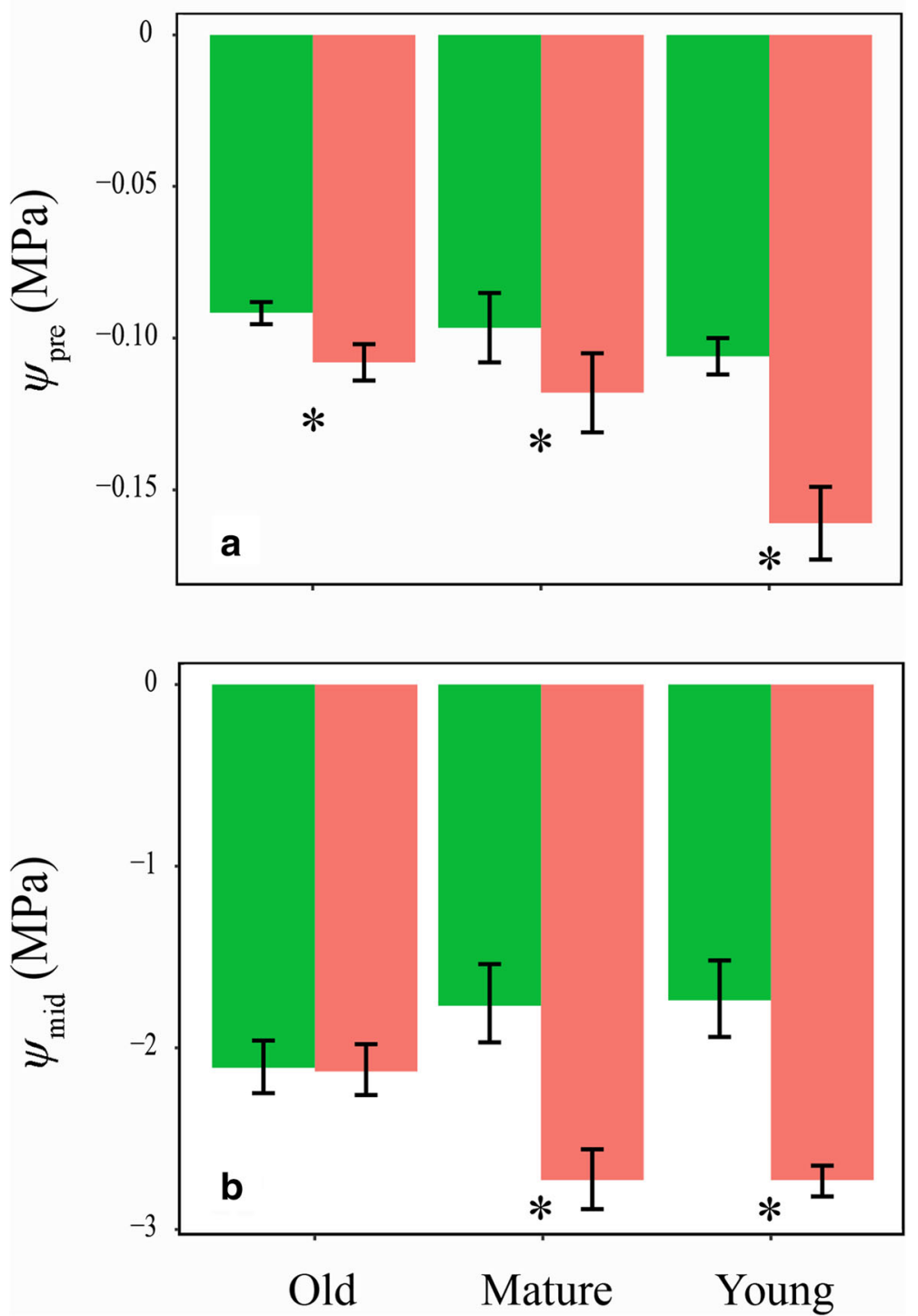

Fig. 5 Leaf water potential at predawn $\left(\psi_{\text {pre, }}\right.$ a) and midday $\left(\psi_{\text {mid }}\right.$, b) for the old, mature and young culms during June to August in 2018 . Error bars represent \pm SEM

stages of culms from June to July under TRT (all $p<0.01$, Fig. 8).

\section{Stomatal density, size and $g_{w(\max )}$}

The TRT increased the stomatal density by $45.4 \%(p=$ $0.03)$ and $59.9 \%(p=0.03)$ in the old and young culms, respectively (Fig. 9a), while decreased the stomatal size of the old culms by $43.5 \%(p<0.01$, Fig. $9 \mathrm{~b})$, which became the smallest among the three developmental stages of culms. Due to the variation of stomatal density and size, $g_{\mathrm{w}(\max )}$ was increased by $13.0 \%(p=0.03)$ and $49.1 \%$ $(p<0.01)$ in the old and young culms under TRT, respectively (Fig. 9c).

\section{Discussion}

The response of sap flow to throughfall reduction

The responses of $J_{\mathrm{s}}$ to TRT were not identical in the three developmental stages of culms, $J_{\mathrm{s}}$ decreased in the mature culms rather than the old and young under TRT. Generally, the mature culms often had the highest specific leaf area and leaf area index (LAI) in all three developmental stages, suggesting highest transpiration demands (Banik 


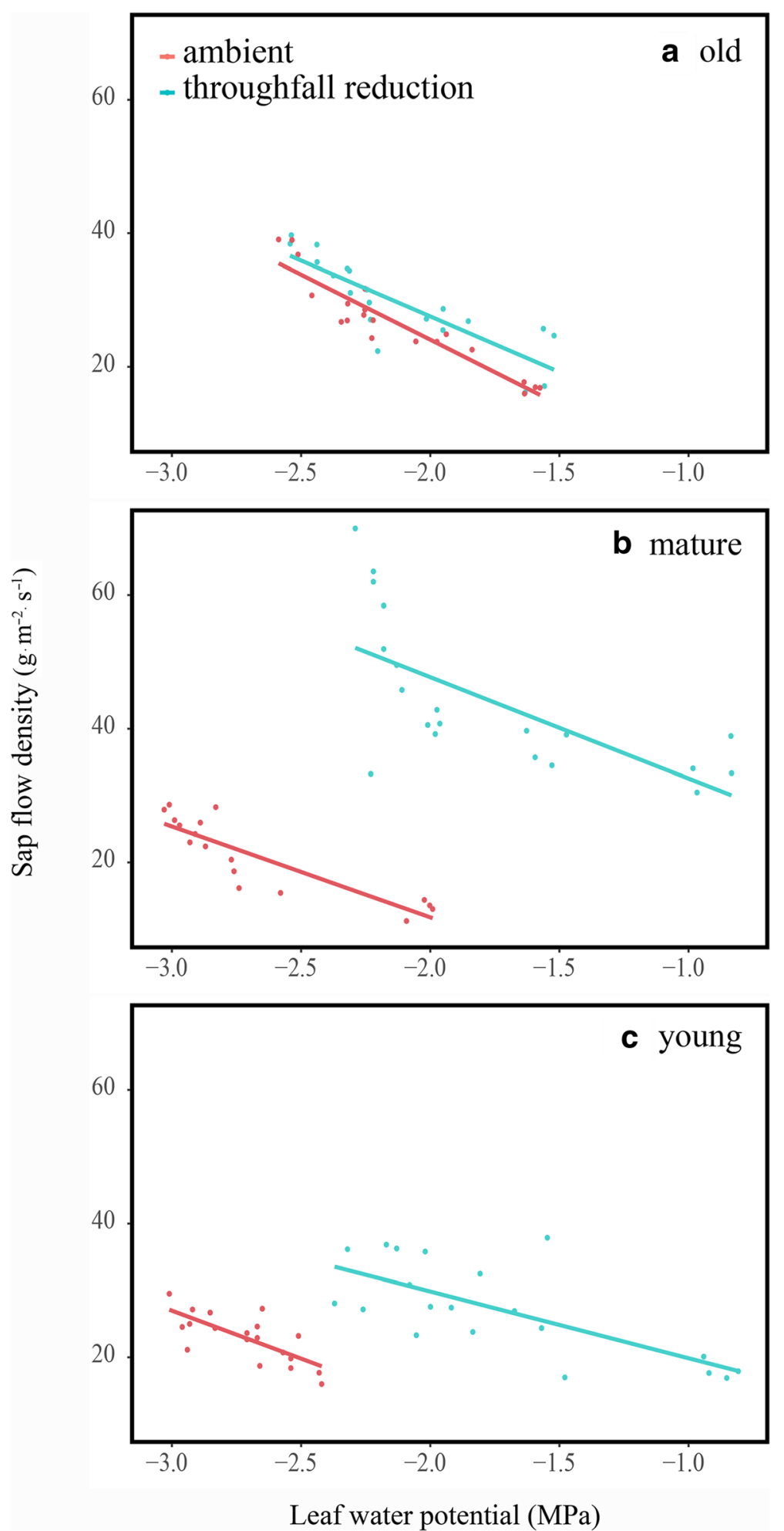

Fig. 6 Relationship between sap flow density $\left(J_{s}\right)$ and leaf water potential at midday (11:00-13:00) for old (a), mature (b) and young culms (c) in ambient (green) and throughfall reduction (red) during June to August in 2018 


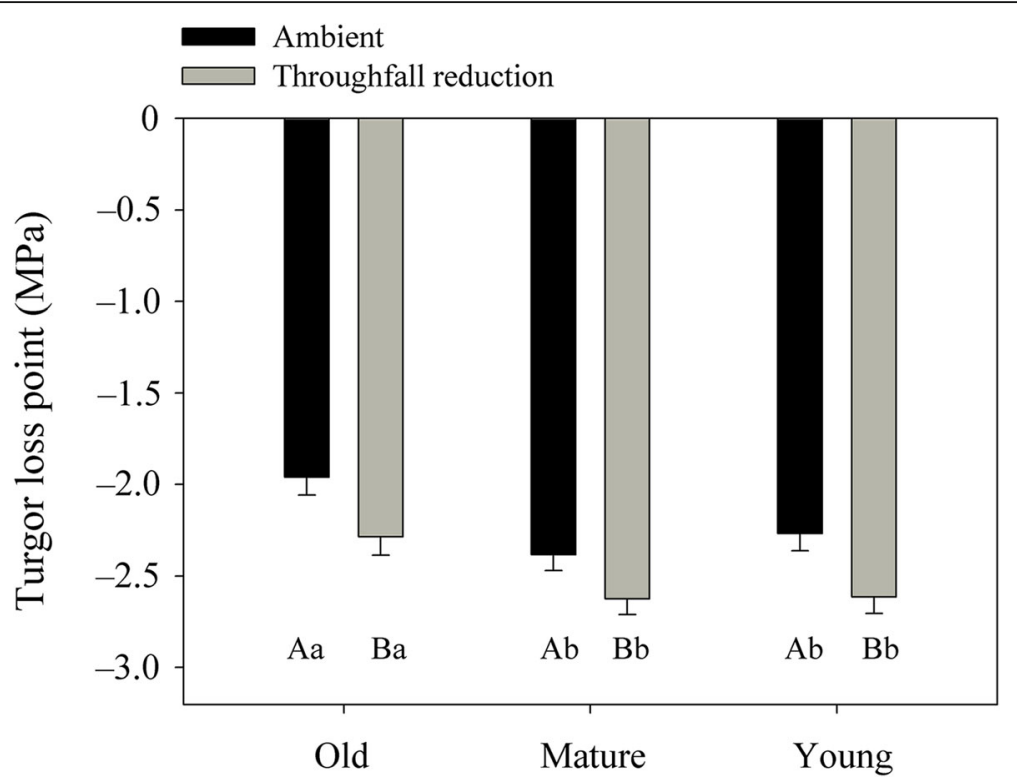

Fig. 7 Mean turgor loss point $\left(\psi_{\text {TLP }}\right)$ for the leaves of three developmental stages of bamboo culms in ambient (black) and throughfall reduction (grey). Different capital letters below the columns indicate significant difference between treatments and the lowercase letters indicate significant difference between three developmental stages of culms $(a<0.05$; Tukey method)

2000; Banik and Islam 2005), and thus they probably were most susceptible to soil water stress. Another reason for the declined $J_{\mathrm{s}}$ in the mature would be the declining stomatal aperture (Hsiao 1973; Cornic 2000; Kuromori et al. 2018). As stomatal aperture directly control the sensitivity of $J_{\mathrm{s}}$ to VPD and PAR (Lawson and Blatt 2014), in turn, the sensitivity of $J_{\mathrm{s}}$ to VPD and PAR reflected the stomatal aperture. In detail, the decreasing sensitivity of $J_{\mathrm{s}}$ to VPD and PAR in the mature culms elucidated their stomatal aperture down regulating. Moreover, the decreasing distance from $\psi_{\text {TLP }}$ supported that the stomatal aperture decreased under TRT. However, reduced stomatal aperture occurred in the old and young culms, which didn't elicit the decrease of $J_{\mathrm{s}}$. The consistent $J_{\mathrm{s}}$ in the young under TRT probably was helped by the water compensated from the mature culms. This was reported that more than $20 \%$ of compensative water was transported to the young culms from culms at other developmental stages (Zhao et al. 2016), and the compensative water helped the young culms maintaining water use, gas exchange activity and net photosynthesis under drought (Adonsou et al. 2016). Moreover, plants could plastically adjust their stomatal traits to respond to drought (Liu et al. 2016). Therefore, the young and the old probably changed their stomatal characteristics to sustain $J_{\mathrm{s}}$ under drought.

\section{Leaf water potential response to throughfall reduction}

The three developmental stages of culms exhibited distinct patterns of $\psi_{\text {mid }}$ variation after TRT, which were attributed to the different responses of $J_{\mathrm{s}}$ to TRT. In other words, plant water status was the result of their water use under drought (Nadezhdina 1999). In fact, negative relationships between $J_{\mathrm{s}}$ and $\psi_{\text {mid }}$ showed in all three developmental stages of culms. Thereby, the declining $J_{\mathrm{s}}$ in the mature culms caused a raise of $\psi_{\text {mid }}$, and similarly, the unchanged $J_{\mathrm{s}}$ in the old culms coupled with consistent $\psi_{\text {mid }}$ under TRT. However, unlike the old, the unchanged $J_{\mathrm{s}}$ accompanied with the decreasing $\psi_{\text {mid }}$ in the young culms. This was explained by the more negative $\psi_{\text {TLP }}$ in the young culms than the old, suggesting the young closed stomatal latter under drought and thus lost more water than the old. The developmental stage-specific responses of $\psi_{\text {leaf }}$ to TRT probably indicated different water use strategies under drought, where the old culm tended to take drought avoidance strategy to conserve water, while the young and mature culm preferred to take drought tolerant strategy.

\section{Stomatal response to throughfall reduction}

Consistent with the different response of $J_{\mathrm{s}}$ among developmental stages, the stomatal density and size also responded differently to drought among developmental stages. The $g_{\mathrm{w}(\max )}$ was increased only for the young and old culms by changing stomatal density and size, but not for the mature culms. We speculate that the young and old culms maintain consistent $J_{\mathrm{s}}$ through the increased $g_{\mathrm{w}(\max )}$ in the context that the stomatal aperture was reduced under TRT, while the decreased $J_{\mathrm{s}}$ of the mature probably was due to the unchanged $g_{\mathrm{w}(\max )}$. Interestingly, different from the young which solely increased stomatal density without 


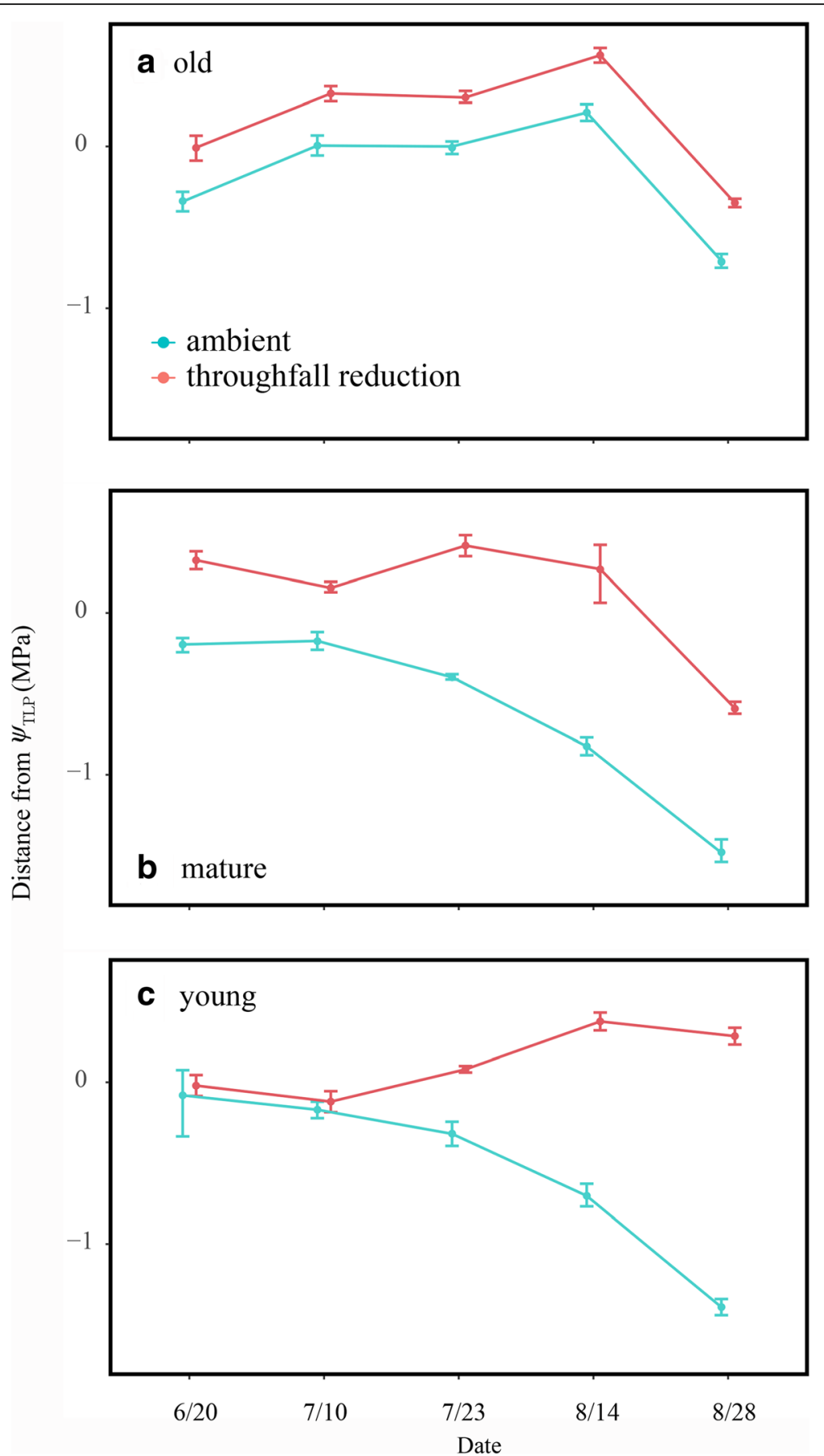

Fig. 8 The difference between leaf water potential $\left(\psi_{\text {mid }}\right)$ and turgor loss point $\left(\psi_{\text {TLP }}\right)$ for the old (a), mature (b) and young (c) culms in ambient (green) and throughfall reduction (red). Error bars represent \pm SEM

changing size, the old culms increased stomatal density but decreased stomatal size. Studies suggested that smaller stomata responded faster to environmental and internal cues (Drake et al. 2013; Kardiman and Ræbild 2017), which means stomata with smaller size closing faster under water stress. Therefore, the risk of hydraulic failure following increased stomatal density could be avoided by lowering stomatal size (Franks et al. 2009). On account of lacking secondary growth, the quantity and quality of functional stem vessels declines with developmental stages, and thus the ability for water uptake and transportation of old bamboos are the worst in three developmental stages of culms (Gielis 2015). Therefore, the old culms encountered the risk of potential hydraulic 

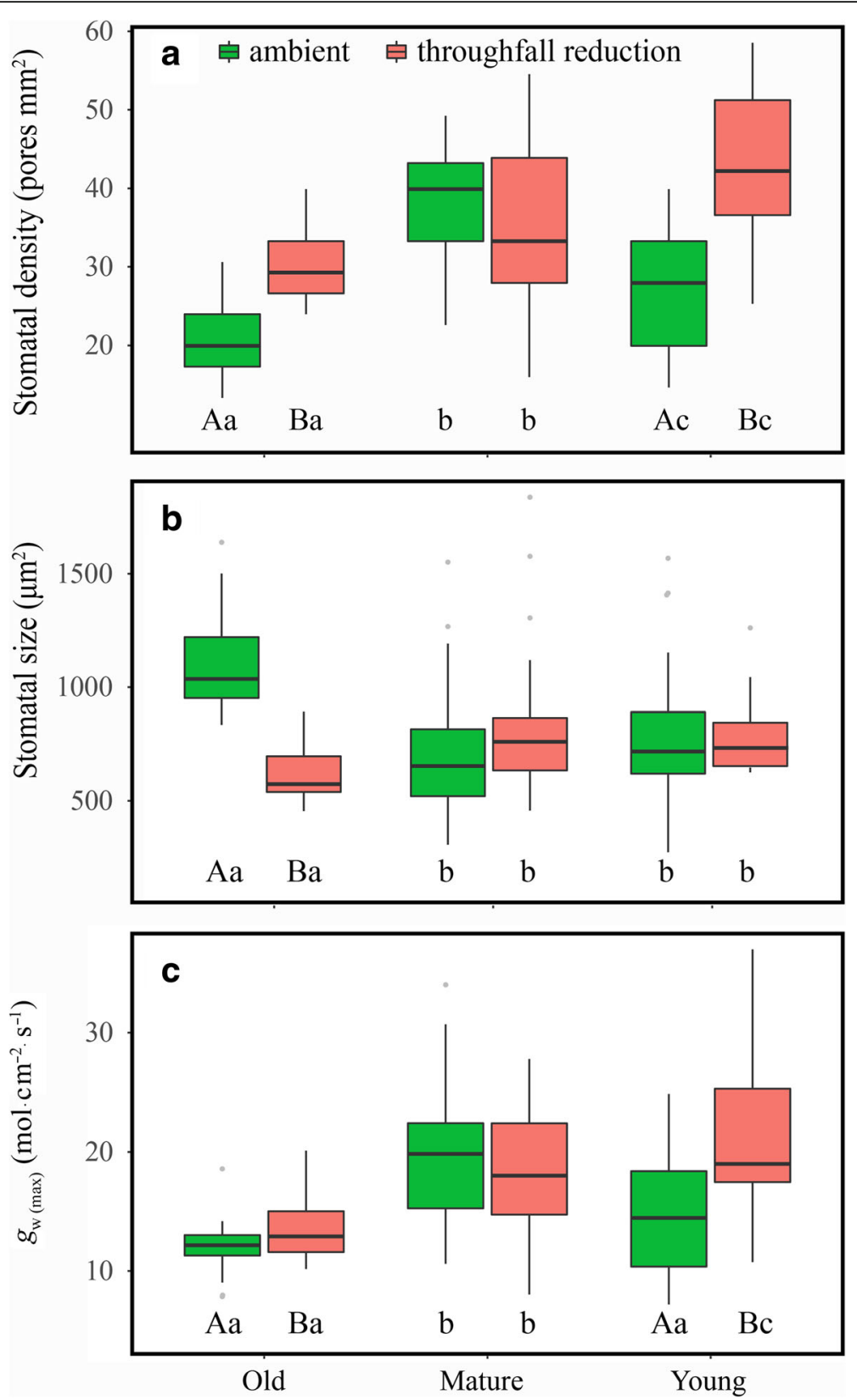

Fig. 9 Stomatal density (a), stomatal size (b) and maximum stomatal conductance $\left(g_{w}(\max )\right.$ (c) in three developmental stages of bamboo culms. The band inside the boxes represent the median, the whiskers upside and underside of box represent the first and third quartiles (25th and 75th percentiles, respectively), and dots correspond to values beyond 1.5x inner quartile range (IQR) from the first and third quartiles. Different capital letters below the columns indicate significant difference between treatments and the lowercase letters indicate significant difference between three developmental stages of culms ( $a<0.05$; Tukey method)

failure while maintaining water use under drought, but the reduced stomatal size coincidently was beneficial to avoid hydraulic failure. Actually, the different patterns of stomatal density and size in response to drought generated different drought sensitivity of water use of the culms at different developmental stages. Water use of the young and old culms were less sensitive to drought than the mature due to their stomatal adjustments. Furthermore, different developmental stages of culms probably triggered various water use strategies under drought.

\section{Different water use strategies to drought}

Disparate trends in $J_{\mathrm{s}}$ and $\psi_{\text {leaf }}$ under TRT indicated different water use strategies in the three developmental 
stages of culms. The consistent $J_{\mathrm{s}}$ and decreased $\psi_{\text {leaf }}$ in the young culms under TRT were characteristic of a drought tolerant strategy, where $J_{\mathrm{s}}$ was sustained at highly negative $\psi_{\text {leaf. }}$. In contrast, a drought avoidance strategy was found in the old culms under TRT, where the $\psi_{\text {mid }}$ did not change and $J_{\mathrm{s}}$ was more sensitive to decreasing $\psi_{\text {leaf }}$ than the young culms, suggesting that the old was more conservative to drought than the young culms. However, a recent study showed that all of three developmental stages of a sympodial bamboo species (Bambusa chungii) adopted the tolerant strategy under drought (Zhang et al. 2017). As the rhizome systems of the sympodial and monopodial bamboo are pronouncedly different, and the sympodial bamboo with tight clumping habit are native to tropical regions with a long dry season (Kleinhenz and Midmore 2001). In the relatively homogeneous habitat, different developmental stages of culms of the sympodial bamboo would be better to resist water deficit by taking the same water use strategy.

\section{Conclusion}

We found different responses of $J_{\mathrm{s}}$ and $\psi_{\text {leaf }}$ in three developmental stages of culms to manipulative drought, which were attributable to the developmental stagespecific structural and physiological variations of stomata. Importantly, the water use of the mature culms was the most sensitive under drought among three developmental stages. Further research is needed to quantify the role of clonal integration in the regulation of structural and physiological traits of bamboo culms at different developmental stages, and how Moso bamboo adjusts the composition of different developmental stages of culms, as well as feedbacks in this adjustment.

\section{Abbreviations \\ A: Ambient; $D$ : Stomatal density; $g_{w(\max )}$. The maximum stomatal conductance; $J_{s}$ : Sap flow density; $p$ : Guard cell length; \\ PAR: Photosynthetically active radiation; Precip.: Precipitation; $\mathrm{RH}$ : Relative humidity; SWC: Soil water content; T: Air temperature; TRT: Throughfall reduction treatment; VPD: Vapor pressure deficit; W: Guard cell pair width; WS: Wind speed; $\psi_{\text {leaf: }}$ Leaf water potential; $\psi_{\text {mid }}$ : Leaf water potential at midday; $\psi_{\text {pre: }}$ Leaf water potential at predawn; $\psi_{\text {TLP }}$ : Leaf water potential at turgor loss}

\section{Acknowledgements}

The authors would like to thank Ping Zhao for technical assistance, and XiaoMin Gao for field and laboratory assistance.

\section{Authors' contributions}

SL, JL and XW designed the research. CC, YW and XW carried out the experiment. XW analyzed the data and wrote the manuscript. All authors read and approved the final manuscript.

\section{Funding}

This research was supported by the National Key R\&D Program of China (2018YFD060010402 and 2018YFC0507301) and the Basic Scientific Research Funds of International Center for Bamboo and Rattan (1632018002,

1632017016, 1632018004 and 1632018008).

\section{Availability of data and materials}

The datasets used during the current study are available from the corresponding author on reasonable request.

Ethics approval and consent to participate

Not applicable.

\section{Consent for publication}

Not applicable.

\section{Competing interests}

The authors declare that they have no competing interests.

\section{Author details}

${ }^{1}$ Key Laboratory of Bamboo and Rattan, International Centre for Bamboo and Rattan, Beijing 100102, China. ${ }^{2}$ Changning Bamboo Forest Ecosystem Research Station, Changning 644300, Sichuan, China. ${ }^{3}$ Key Laboratory of Forest Ecology and Environment, National Forestry and Grassland Administration, Institute of Forest Ecology, Environment and Protection, Chinese Academy of Forestry, Beijing 100091, China.

Received: 13 April 2019 Accepted: 4 June 2019

Published online: 14 June 2019

\section{References}

Adonsou KE, DesRochers A, Tremblay F (2016) Physiological integration of connected balsam poplar ramets. Tree Physiol 36:797-806

Allen RG, Pereira LS, Raes D (1998) Crop evapotranspiration-guidelines for computing Crop Water Requirements-FAO Irrigation \& Drainage Paper. Fao Rome 9:D05109

Anderegg WR, Kane JM, Anderegg LD (2013) Consequences of widespread tree mortality triggered by drought and temperature stress. Nat Clim Chang 3:30

Attia Z, Domec JC, Oren R, Way DA, Moshelion M (2015) Growth and physiological responses of isohydric and anisohydric poplars to drought. J Exp Bot 66:4373-4381

Banik RL (2000) Silviculture and field-guide to priority bamboos of Bangladesh and South Asia. BFRl, Chittagong:1-187

Banik RL, Islam SAMN (2005) Leaf dynamics and above ground biomass growth in Dendrocalamus longispathus Kurz. J Bamboo Rattan 4:143-150

Barbeta A, Mejía-Chang M, Ogaya R, Voltas J, Dawson TE, Peñuelas J (2015) The combined effects of a long-term experimental drought and an extreme drought on the use of plant-water sources in a Mediterranean forest. Glob Change Biol 21:1213-1225

Bartlett MK, Zhang Y, Kreidler N, Sun S, Ardy R, Cao K, Sack L (2014) Global analysis of plasticity in turgor loss point, a key drought tolerance trait. Ecol Lett 17:1580-1590

Bates D, Mächler M, Bolker B, Walker S (2015) Fitting linear mixed-effects models using Ime4. J Stat Softw 67

Bosabalidis AM, Kofidis G (2002) Comparative effects of drought stress on leaf anatomy of two olive cultivars. Plant Sci 163:375-379

Bretfeld M, Ewers BE, Hall JS (2018) Plant water use responses along secondary forest succession during the 2015-2016 El Nino drought in Panama. New Phytol (3):885-899

Cornic G (2000) Drought stress inhibits photosynthesis by decreasing stomatal aperture-not by affecting ATP synthesis. Trend Plant Sci 5:187-188

Dong BC, Alpert P, Zhang Q, Yu FH (2015) Clonal integration in homogeneous environments increases performance of Alternanthera philoxeroides. Oecologia 179:393-403

Drake PL, Froend RH, Franks PJ (2013) Smaller, faster stomata: scaling of stomatal size, rate of response, and stomatal conductance. J Exp Bot 64:495-505

Du S, Wang Y-L, Kume T, Zhang J-G, Otsuki K, Yamanaka N, Liu G-B (2011) Sapflow characteristics and climatic responses in three forest species in the semiarid loess plateau region of China. Agr Forest Meteor 151:1-10

Forner A, Aranda I, Granier A, Valladares F (2014) Differential impact of the most extreme drought event over the last half century on growth and sap flow in two coexisting Mediterranean trees. Plant Ecol 215:703-719

Franks PJ, Doheny-Adams TW, Britton-Harper ZJ, Gray JE (2015) Increasing wateruse efficiency directly through genetic manipulation of stomatal density. New Phytol 207:188-195

Franks PJ, Drake PL, Beerling DJ (2009) Plasticity in maximum stomatal conductance constrained by negative correlation between stomatal size and 
density: an analysis using Eucalyptus globulus. Plant Cell Environ 32:17371748

Franks PJ, Farquhar GD (2007) The mechanical diversity of stomata and its significance in gas-exchange control. Plant Physiol 143:78-87

Fraser LH, Greenall A, Carlyle C, Turkington R, Friedman CR (2009) Adaptive phenotypic plasticity of Pseudoroegneria spicata: response of stomatal density, leaf area and biomass to changes in water supply and increased temperature. Ann Bot 103:769-775

Gielis J (2015) Bamboo-The plant and its uses. J Am Bamboo Soc, Springer International Publishing AG Switzerland, p 40

Granier A (1987) Evaluation of transpiration in a Douglas-fir stand by means of sap flow measurements. Tree Physiol 3:309-320

Grossiord C, Gessler A, Granier A, Pollastrini M, Bussotti F, Bonal D (2014) Interspecific competition influences the response of oak transpiration to increasing drought stress in a mixed Mediterranean forest. Forest Ecol Manag 318:54-61

Hochberg U, Rockwell FE, Holbrook NM, Cochard H (2018) Iso/Anisohydry: a plant-environment interaction rather than a simple hydraulic trait. Trend Plant Sci 23:112-120

Hothorn T, Bretz F, Westfall P (2008) Simultaneous inference in general parametric models. Biom J 50:346-363

Hsiao TC (1973) Plant responses to water stress. Ann Rev Plant Physiol 24: 519-570

Kardiman R, Ræbild A (2017) Relationship between stomatal density, size and speed of opening in Sumatran rainforest species. Tree Physiol 38:1-10

Kleinhenz V, Midmore DJ (2001) Aspects of bamboo agronomy. Adv Agron 74:99-153

Koide RT, Robichaux RH, Morse SR, Smith CM (1989) Plant water status, hydraulic resistance and capacitance. Plant physiological ecology. Springer, pp 161-183

Kuromori T, Seo M, Shinozaki K (2018) ABA transport and plant water stress responses. Trend Plant Sci 23:513-522

Lawson T, Blatt MR (2014) Stomatal size, speed, and responsiveness impact on photosynthesis and water use efficiency. Plant Physiol 164:1556-1570

Lindeman RH, Merenda PF, Gold RZ (1980) Introduction to bivariate and multivariate analysis. Scott, Foresman and Company, Glenview, IL, p $1119 \mathrm{ff}$

Liu F, Liu J, Dong M (2016) Ecological consequences of clonal integration in plants. Front Plant Sci 7:770

Liu J, Zhang F, Zhou J, Chen F, Wang B, Xie X (2012) Phytochrome B control of total leaf area and stomatal density affects drought tolerance in rice. Plant Mol Biol 78:289-300

Maréchaux I, Bartlett MK, Sack L, Baraloto C, Engel J, Joetzjer E, Chave J (2015) Drought tolerance as predicted by leaf water potential at turgor loss point varies strongly across species within an Amazonian forest. Funct Ecol 29: 1268-1277

Mata RDL, Merlo E, Zas R (2014) Among-population variation and plasticity to drought of Atlantic, Mediterranean, and interprovenance hybrid populations of maritime pine. Tree Genet Genomes 10:1191-1203

Meinzer FC, Woodruff DR, Eissenstat DM, Lin HS, Adams TS, McCulloh KA (2013) Above-and belowground controls on water use by trees of different wood types in an eastern US deciduous forest. Tree Physiol 33:345-356

Meinzer FC, Woodruff DR, Marias DE, Smith DD, McCulloh KA, Howard A, Magedman AL (2016) Mapping 'hydroscapes' along the iso- to anisohydric continuum of stomatal regulation of plant water status. Ecol Lett 19:1343-1352

Nadezhdina N (1999) Sap flow index as an indicator of plant water status. Tree Physiol 19:885-891

Pinheiro HA, DaMATTA FM, Chaves AR, Loureiro ME, Ducatti C (2005) Drought tolerance is associated with rooting depth and stomatal control of water use in clones of Coffea canephora. Ann Bot 96:101-108

R Core Team (2017) R: A language and environment for statistical computing. $R$ Foundation for Statistical Computing, Vienna, Austria

Roiloa S, Antelo B, Retuerto R (2014) Physiological integration modifies $\delta^{15} \mathrm{~N}$ in the clonal plant Fragaria vesca, suggesting preferential transport of nitrogen to water-stressed offspring. Ann Bot 114:399-411

Schultz HR (2003) Differences in hydraulic architecture account for near-isohydric and anisohydric behaviour of two field-grown Vitis vinifera $L$. cultivars during drought. Plant Cell Environ 26:1393-1405

Sevanto S, Mcdowell NG, Dickman LT, Pangle R, Pockman WT (2014) How do trees die? A test of the hydraulic failure and carbon starvation hypotheses. Plant Cell Environ 37:153-161
Skelton RP, West AG, Dawson TE (2015) Predicting plant vulnerability to drought in biodiverse regions using functional traits. P Natl A Sci 112:5744-5749

Song X, Peng C, Zhou G, Gu H, Li Q, Zhang C (2016) Dynamic allocation and transfer of non-structural carbohydrates, a possible mechanism for the explosive growth of Moso bamboo (Phyllostachys heterocycla). Sci Rep 6:25908

Sun Y, Yan F, Cui X, Liu F (2014) Plasticity in stomatal size and density of potato leaves under different irrigation and phosphorus regimes. J Plant Physiol 171: 1248-1255

van Kleunen M, Stuefer JF (1999) Quantifying the effects of reciprocal assimilate and water translocation in a clonal plant by the use of steam-girdling. Oikos 85:135-145

Wang L, Chen W (2014) A CMIP5 multimodel projection of future temperature, precipitation, and climatological drought in China. Int J Climatol 34:2059-2078

Xu ZZ, Zhou GS, Shimizu H (2009) Effects of soil drought with nocturnal warming on leaf stomatal traits and mesophyll cell ultrastructure of a perennial grass. Crop Sci 49:1843-1851

Yan W, Zhong Y, Shangguan Z (2016) A meta-analysis of leaf gas exchange and water status responses to drought. Sci Rep 6:20917

You W, Yu D, Liu C, Xie D, Xiong W (2013) Clonal integration facilitates invasiveness of the alien aquatic plant Myriophyllum aquaticum L. under heterogeneous water availability. Hydrobiologia 718:27-39

Zhang H, Liu F, Wang R, Liu J (2016) Roles of clonal integration in both heterogeneous and homogeneous habitats. Front Plant Sci 7:551

Zhang Z, Zhou J, Zhao X, Zhao P, Zhu L, Ouyang L, Ni G (2017) Maximised photosynthetic capacity and decreased hydraulic failure risk during aging in the clump bamboo, Bambusa chungii. Funct Plant Biol 44:785

Zhao X, Zhao P, Zhang Z, Zhu L, Hu Y, Ouyang L, Ni G, Ye Q (2017) Culm age and rhizome affects night-time water recharge in the bamboo Phyllostachys pubescens. Front Plant Sci 8:1928

Zhao X, Zhao P, Zhang Z, Zhu L, J-f N, Ni G, Hu Y, Ouyang L (2016) Sap flowbased transpiration in Phyllostachys pubescens: applicability of the TDP methodology, age effect and rhizome role. Trees 31:765-779

Zhou G, Wei X, Wu Y, Liu S, Huang Y, Yan J, Zhang D, Zhang Q, Liu J, Meng Z (2011) Quantifying the hydrological responses to climate change in an intact forested small watershed in southern China. Glob Chang Biol 17:3736-3746

\section{Submit your manuscript to a SpringerOpen ${ }^{\circ}$ journal and benefit from:}

- Convenient online submission

Rigorous peer review

- Open access: articles freely available online

- High visibility within the field

- Retaining the copyright to your article

Submit your next manuscript at $\boldsymbol{\nabla}$ springeropen.com 